\title{
A ilusão de Paschoal ou Cinco efeitos negativos do impeachment de Jair Bolsonaro para a esquerda e para a democracia no Brasil
}

L'illusion de Paschoal ou Cinq effets négatifs de l'impeachment de Jair Bolsonaro pour la gauche et pour la démocratie au Brésil La ilusión de Paschoal o cinco efectos negativos del impeachment de Jair Bolsonaro para la izquierda y para la democracia en Brasil The illusion of Paschoal, or Five negative effects from the impeachment of President Jair Bolsonaro for the left and for the Brazilian democracy

\section{Guilherme Ribeiro}

\section{OpenEdition}

Journals

\section{Edição electrónica}

URL: http://journals.openedition.org/espacoeconomia/11721

DOI: 10.4000/espacoeconomia. 11721

ISSN: 2317-7837

\section{Editora}

Núcleo de Pesquisa Espaço \& Economia

Refêrencia eletrónica

Guilherme Ribeiro, «A ilusão de Paschoal ou Cinco efeitos negativos do impeachment de Jair Bolsonaro para a esquerda e para a democracia no Brasil ", Espaço e Economia [Online], 18 | 2020, posto online no dia 23 abril 2020, consultado o 21 maio 2020. URL : http://journals.openedition.org/ espacoeconomia/11721; DOI : https://doi.org/10.4000/espacoeconomia.11721

Este documento foi criado de forma automática no dia 21 maio 2020.

(C) NUPEE 


\title{
A ilusão de Paschoal ou Cinco efeitos negativos do impeachment de Jair Bolsonaro para a esquerda e para a democracia no Brasil
}

\author{
L'illusion de Paschoal ou Cinq effets négatifs de l'impeachment de Jair Bolsonaro \\ pour la gauche et pour la démocratie au Brésil \\ La ilusión de Paschoal o cinco efectos negativos del impeachment de Jair \\ Bolsonaro para la izquierda y para la democracia en Brasil \\ The illusion of Paschoal, or Five negative effects from the impeachment of \\ President Jair Bolsonaro for the left and for the Brazilian democracy
}

Guilherme Ribeiro

Nos últimos vinte anos, tenho tido a chance de aprender de perto com interlocutores do porte e da generosidade de Floriano Godinho de Oliveira (PPFH/UERJ) e Leandro Dias de Oliveira (PPGGEO/UFRRJ). Mais recentemente, o convívio com Pablo Ibañez (DG/UFRRJ) redirecionou meu olhar para as particularidades da politica brasileira. Colegas como Leonardo Chagas de Brito, João Alves de Souza Neto, Zilmar Luiz dos Reis Agostinho, Rafael Wionoscky Garcia, Fábio Moreira Barcellos e Ismael Lauria fizeram leituras substanciais de versões iniciais desse texto $e$ pude beneficiar-me de várias de suas observações. Separo, notadamente, as lições sobre política compartilhadas pela inteligência sensível de Isabô Lauria.

\section{Exórdio: um problema de monta para a esquerda brasileira}

1 A leitura da excelente reportagem da piauí sobre o impeachment de Dilma Roussef entre 2015 e $2016{ }^{1}$ desnuda a trama indigesta costurada pela principal mentora da idéia, Janaina Paschoal, e posta em prática pelo grupo político responsável por toda a transação, liderado pelo fenomenal Eduardo Cunha instalado na Presidência da Câmara dos Deputados. Sob incipiente alegação das pedaladas fiscais, a direita foi premiada com 
o álibi oportunista da vez e retornou ao poder por meio da indescritível figura de Michel Temer.

2 Abria-se, assim, não só oportunidade para a efetivação de reformas neoliberais como a trabalhista e a PEC do "Fim do Mundo" ${ }^{2}$, mas também para a prisão política do principal nome da esquerda brasileira sob a chancela "legal" da Operação Lava-Jato. Perseguido até às últimas consequências pelo juiz de primeira instância Sergio Moro, Lula esteve longe de receber julgamento imparcial. Tal como ocorrera com a destituição de Roussef, tratou-se de inescrupulosa prestidigitação político-jurídica de ampla repercussão midiática visando a retirada do maior nome da esquerda brasileira do pleito presidencial.

3 Eis montado o cenário para o ovo da serpente que estava por vir: Jair Bolsonaro, o espectro da ditadura militar, sairia dos bastidores para o centro do palco vociferando em carne e osso contra partidos, instituições e mídia hegemônica em nome de Deus, da Pátria e da Família. O apoio maciço do neopentecostalismo revestiu a tragédia de dimensões irracionais e a difusão pelas redes sociais de fake news sem precedentes contra o Partido dos Trabalhadores consagrou a era da pós-verdade em um país não por acaso caracterizado por rarefeita consciência política. Não há como interpretar isso senão como um verdadeiro retrocesso, pois tanto a educação, a pesquisa científica e a universidade passam a ser menosprezadas quanto os próprios partidos são deslocados às custas de afinidades esotéricas - e, portanto, "inquestionáveis". Da "defesa" do terraplanismo à rejeição do darwinismo e à tentativa inquisitorial de proibição de determinados livros, o corolário é a atrofia da esfera pública. A aliança entre política e religião no Brasil atual não exprime o quanto ambas estão degradadas?

4 Nas últimas semanas, os jornais noticiaram a iniciativa da agora deputada estadual Janaina Paschoal pelo PSL paulista - cuja votação para tal cargo tornou-se a maior da história do país - de reclamar o impeachment daquele que outrora fora seu candidato inquestionável à Presidência da República. Motivo aparente: em tempos de pandemia do Covid-19, atentado à saúde pública ao cumprimentar correligionários em Brasília durante manifestação em prol de seu governo. Dias depois, texto de reconhecido jornalista ligado ao Partido dos Trabalhadores caminha em direção similar à de Paschoal clamando pela renúncia do presidente. Na sequência, parte considerável de meus vizinhos de bairro aderiu ao "panelaço" convocado pelas redes bradando "Fora, Bolsonaro". Aqui, lembrar que tal estratégia foi adotada pela direita brasileira como pressão pelo impeachment de Dilma Roussef não é mero detalhe. Quando a esquerda compartilha a mesma prática da direita, ainda que motivada por um inconsciente desejo de vingança, estamos diante de um sinal de alerta.

5 Movimentos superficiais não devem confundir a compreensão de processos estruturais mais amplos. A defesa da democracia, da ampliação do espaço público e da própria História em uma formação sócio-espacial há séculos dominada pela elite do atraso ${ }^{3}$ não podem ser submetidas ao presentismo, ao revanchismo e, tampouco, ao oportunismo político-partidário.

6 Embora parta de algo que não existe e que pode mesmo nunca acontecer, nem por isso a reflexão em tela perde seu valor. 0 impeachment como maquiavelismo de uma fração da direita visando permanecer no poder e cinco desdobramentos negativos para a esquerda e para a democracia brasileiras: eis o conteúdo das linhas a seguir. 


\section{Sobre um possível impeachment de Jair Bolsonaro: cinco efeitos}

7 Ao levantar a bandeira do impeachment de Bolsonaro, o efeito mais imediato é o conduzir à Presidência um general da reserva incapaz de proferir uma sílaba contra os anos de chumbo. Correção: incapaz de admitir a existência da ditadura militar no Brasil entre 1964 e 1985. Aceitar a posição de vice não foi decisão ingênua, evidentemente nem de sua parte, nem da de Bolsonaro. Embora algumas declarações iniciais tenham contrariado seu superior, Hamilton Mourão alimenta-se diariamente do mesmo fruto que Bolsonaro e seus asseclas. Ele pertence a um segmento da sociedade para quem o período dos militares no poder trouxe mais benefícios que malefícios - sobretudo no que se refere à narrativa segundo a qual uma "ameaça comunista" rondava o país naquela ocasião. Assinada pelo general do Exército e ministro da Defesa Fernando Azevedo e Silva, a ordem do dia publicada no site do Ministério da Defesa por ocasião dos cinquenta e seis anos do Movimento de 1964 - sim, eles não usam a palavra golpe neste caso, mas não temos dúvidas de que o farão caso Bolsonaro seja destituído do poder - continua a reproduzir tal versão, sustentando literalmente tratar-se de um "marco para a democracia brasileira", além de definir a Lei da Anistia de 1979 como um "pacto de pacificação" (Azevedo e Silva 2020). No Twitter, o próprio Mourão não se faz de rogado e anota que a intervenção militar sobreveio para "enfrentar a desordem, subversão e corrupção que abalavam as instituições e assustavam a população". Neste contexto, empossá-lo significará reforçar no imaginário popular o papel "salvífico" dos militares em meio ao "caos" da vida política nacional, contribuindo não só para garantir espaço aos mesmos na esfera democrática quanto para perpetuar a nostalgia dos saudosos do AI-5 ${ }^{4}$.

8 Levando adiante este raciocínio, partindo dos pressupostos segundo os quais valores militares e valores democráticos são incompatíveis e a direita brasileira não tem compromisso algum com a democracia, devemos levantar a voz mesmo diante de interrogação tão sombria: quem garantirá que Mourão, o general Augusto Heleno, o presidente do Supremo Tribunal Federal Dias Toffoli, Sergio Moro, deputados do PSL e boa parte do Parlamento não darão um golpe à la 1964? Pior: receberiam aval incondicional de quase sessenta milhões de patriotas, à espera da solução mais autoritária possível desde que confiaram seus votos a Jair Bolsonaro. A esquerda não pode se iludir quanto a isto: parte considerável da sociedade brasileira está em sentinela por um golpe militar.

9 Por fim, os que não se incomodam com o livre pensamento avistarão mais que contrafactualidade na pergunta em tela: seria o impeachment aventado como opção política pela direita se ao invés de Mourão o vice-presidente fosse alguém de esquerda?

10 Os dois próximos efeitos operam no nível da consciência histórica ${ }^{5} e$, embora inicialmente possam parecer contraditórios, uma observação mais atenta constatará que estão dialeticamente entrelaçados.

11 O segundo efeito terá o papel de reforçar, com o passar do tempo, a dimensão mítica imputada a Bolsonaro por seu séquito tão agressivo quanto infantil. Supondo a consecução do impeachment acompanhado porém da manutenção de seus direitos políticos, ele, seus filhos e netos serão eleitos pelos próximos cem anos sob a justificativa de que o "mito" fora apeado do poder por forças retrógadas que o impediram de realizar todas as transformações de que o Brasil precisava. À maneira de uma prece, seu sobrenome e sua imagem serão evocados como o homem que, eleito 
pelo povo com ampla margem de votos em ambos os turnos, fora retirado da Presidência sem provas, sem motivo, sem razão de ser. Melhor dizendo, isto tudo aconteceu porque ele estava de fato mudando o Brasil. Se num primeiro momento o impeachment cessará seu mandato, a consequência a médio e longo prazos é a de que Bolsonaro entrará fortalecido para a história dos vencedores e da pior forma possível: como ilusão. E, contra a ilusão, a ciência, a verdade e a realidade são pura miragem.

O terceiro efeito incide notadamente sobre a forma como a democracia é representada e acionada entre nós. Se a raison d'être das mobilizações à direita e à esquerda em torno do impeachment de Bolsonaro jaz na insatisfação para com os rumos governamentais após um ano e dois meses de mandato, então automaticamente estaremos autenticando o impeachment de Roussef e, assim, não será mais possível interpretá-lo como o que ele indubitavelmente foi: um golpe da direita contra a esquerda e contra a democracia em geral. A “ilusão de Paschoal" terá triunfado e, como abutres à espreita da caça, conquistado lugar cativo no imaginário político da nação.

13 Em um país sem memória, partidos, empresas, mídia, evangélicos, católicos, professores, empreendedores, todos encontrarão no impeachment o álibi perfeito para a ignorância política e para o surto de amnésia a emergir muito em breve nos próximos anos. Em ambos os casos não haverá vacina disponível, pois tais organismos são incompatíveis com o saber, a cultura, a história e, no limite, não se interessam em nada pela Política já que inaptos para reconhecê-la. A educação segundo Abraham Weintraub, o neoliberalismo servil de Paulo Guedes ${ }^{6}$, a inesquecível ostentação nazifascista de Roberto Alvim, a teocracia medieval de Damares Alves e a realidade paralela de Jair Bolsonaro não podem ser olvidadas, minimizadas ou tidas como excepcionais. Os mais de cinquenta e sete milhões de votos confiados ao mito não podem virar pó; à maneira de seu profundo engajamento como cabos eleitorais incansáveis nas redes sociais disseminando fake news, eles precisam ser co-responsáveis pelos ministros, pelo modus operandi do governo e pelo Brasil como um todo, pois é assim que eleitores formam sua memória política, a democracia amadurece e ensaia romper com o abismo entre sociedade e Estado - ou, em termos conceituais, com a perniciosa atitude que restringe o jogo democrático à conjuntura eleitoral, a chamada democracia delegativa ${ }^{7}$.

o quarto efeito assemelha-se a um jogo de cena. Todavia, há que se deixar a ingenuidade de lado e ter clareza meridiana de que tanto o apoio ao impeachment de Roussef quanto ao projeto de morte sustentado por Bolsonaro desde a gênese de sua candidatura não têm nada que ver com a insatisfação popular em relação à economia no segundo governo Dilma ou com a corrupção envolvendo o Partido dos Trabalhadores e o capital privado nacional ${ }^{8}$. Tal discurso não passa de cortina de fumaça a tentar dissimular que as raízes estruturais de tão propagada insatisfação residem no profundo conservadorismo das elites nacionais e que esta ideologia dominante, propagada com toda força pela mass media, igrejas e escolas, atinge a classe média e dramaticamente a classe trabalhadora.

15 Logo, precisamos enxergar a ilusão de Paschoal sob a perspectiva de uma manobra estratégica capitaneada pela direita a qual, envolvida em disputas intestinas devido à incapacidade política de Bolsonaro em negociar autoridade e legitimidade para o Executivo junto ao Congresso Nacional, se vê na obrigação não só de pensar em um novo nome apto a representá-la como de apresentar-se à população como se inconformada estivesse com a atual situação - eximindo-se, assim, aparentemente, de sua participação ativa em todas as tramas que contribuíram para que as coisas estejam 
exatamente como estão. Assumindo a condição de traída pelo mito ${ }^{9}$, o passo seguinte da direita será a encenação do papel de vítima como parte de um processo de expiação e de purificação de todos os que venderam suas almas sem nenhum conhecimento de causa...

Verdadeiramente, Bolsonaro nunca está e nunca estará à vontade no cargo de Presidente da República pelo simples fato de que nada o convence de que a natureza de um regime democrático consiste em dialogar, escutar, aguardar, retroceder. Suas reações estapafúrdias a tudo aquilo que minimamente lhe desagrada - imprensa livre, pesquisas de órgãos científicos reconhecidos no Brasil e no mundo, educação laica e distante do militarismo - deitam raízes não apenas no solo militar que o nutriu, mas em um período da história ocidental no qual estruturas como o pátrio poder, o rei e a igreja eram incontestáveis ${ }^{10}$. Ele não aproximou-se da religião por acaso: ao evocar repetidas vezes João 8:32 em toda e qualquer circunstância, é como se ele próprio fosse a personificação da verdade encarnada na política. Sua palavra quer ter a força da lei. Sua eleição foi divina e, por conseguinte, irrefutável.

Preso por indisciplina quando capitão do Exército por publicar artigo em semanário de ampla circulação reclamando de perdas salariais logo após a redemocratização em 1986 ${ }^{11}$ e culpado pelo Conselho de Justificação porém absolvido pelo Supremo Tribunal Militar de um processo interno até hoje polêmico referente à elaboração e detonação de bombas-relógio em $1988^{12}$, ao optar pela vida política mostrou comportamento errático até mesmo para os padrões partidários nacionais. Bolsonaro já passou por nove siglas desde 1988 e não está filiado a nenhuma delas desde novembro de 2019.

Tais ocorrências servem não apenas para manifestar nosso espanto diante da ingenuidade dos que esperavam atitudes comedidas e diplomáticas da parte dele ao assumir a Presidência, mas para argumentar que a direita brasileira vinha enfrentando uma crise com as quatro eleições presidenciais vencidas pelo PT a partir de 2003. Muito embora o segundo êxito de Roussef viesse acompanhado de evidente reação conservadora por causa do disputado pleito contra Aécio Neves $(51,64 \%$ ou 54.501 .118 votos para ela e $48,36 \%$ ou 51.041 .155 votos para ele), a subsequente incapacidade de renovação do PSDB e da direita em geral fazem do golpe contra ela e da prisão de Lula via Lava Jato componentes essenciais do assalto ao poder pela elite do atraso. Ocorre que Temer (ele próprio livrado pelo Parlamento de duas denúncias relacionadas à organização criminosa e obstrução de Justiça), diversos integrantes de seu partido (MDB) e de outras agremiações (como o DEM) não foram hábeis o suficiente para costurar um pacto na escala nacional seja porque tornaram-se progressivamente alvos de processos jurídicos de toda sorte - gente da estirpe de Moreira Franco, Romero Jucá, Eliseu Padilha, Eunício Oliveira, Geddel Vieira Lima, Renan Calheiros, Henrique Eduardo Alves, Edison Lobão, Eduardo Cunha, Sergio Cabral... - minando, assim, pretensões mais amplas junto à opinião pública, seja porque parte significativa da elite nacional estava confortavelmente representada por congressistas e ministros participantes dos governos do PT ${ }^{13}$. Insípido e histriônico deputado do baixo clero parlamentar e dono de alcance político irrisório, gostaríamos de sugerir que o advento da candidatura Bolsonaro pode ser analisado como um vácuo de poder no interior da própria direita, e seus métodos políticos, suas redes de baixa capilaridade junto ao empresariado e as conexões com milicianos são sinais reveladores a expressar a visível diferença entre os emergentes Joice Hasselmann, Alexandre Frota, Daniel Silveira, Rodrigo Amorim, Helio Bolsonaro, Kim Kataguiri, Fernando Holiday, Janaina Paschoal e o grupo acima listado. 
Em suma, talvez esteja em curso uma mudança na configuração de um segmento da direita no Brasil em termos de origem social, linguagem e comunicação com o povo. A pauta, no entanto, é a mais retrógada possível.

O quinto e último efeito aponta para a sinistra ${ }^{14}$. Sendo pauta oriunda da direita visando exclusivamente sua manutenção no poder, o impeachment não favorecerá a esquerda nem agora, nem tão cedo. A cassação do mandato de Bolsonaro será não só mais uma prova cabal da volatilidade dos partidos como estimulará o argumento de que ambos os impeachments foram reações legítimas do parlamento e da sociedade civil "conscientes de seus deveres"... O impeachment isenta a todos e, ao invés de abrir o debate democrático, encerra-o ao projetá-lo no terreno das brechas e das manobras jurídicas. O fundamento e a intenção políticos são sufocados. Professora de Direito da Universidade de São Paulo, Janaina Paschoal finge ignorar isto ${ }^{15}$.

Em linhas gerais, e a título de hipótese, aventa-se que a crise teórica e prática decorrente do fim do Socialismo Real no final do século XX foi ignorada pelas históricas e sucessivas vitórias do Partido dos Trabalhadores no início do século XXI. Elas anestesiaram a esquerda nacional. Talvez a quarentena imposta pelo Covid-19 possa simbolizar uma espécie de chamamento e de pausa a fim de avaliarmos com a devida profundidade porquê perdemos a eleição passada e como podemos construir um projeto alternativo. Sem minimizar a Lava Jato e todo o fervor midiático ao seu redor, preferimos optar por uma interpretação que considere com a devida gravidade o fato de que mesmo em uma sociedade estruturalmente conservadora como a nossa o êxito de Bolsonaro foi uma falha da esquerda, cujas quatro vitórias nacionais consecutivas aguçaram a sempre sensível percepção da direita de que qualquer mudança resultará em ameaça aos seus privilégios e ao seu ethos. Em um país como o Brasil, não é preciso muito para que o precedente do autoritarismo seja aberto. Ele já o foi - e o campo progressista não deve minimizar isto.

21 Igualmente, não é prudente postergar a devida auto-crítica em relação aos quatorze anos do Partido dos Trabalhadores no poder ${ }^{16}$. Do matrimônio com o MDB tanto na escala nacional quanto no Rio de Janeiro ao diálogo com a sociedade civil durante e após as Jornadas de Junho de 2013, passando pela consórcio com empreiteiras nacionais promotoras de obras onerosíssimas demandadas pela Copa do Mundo de 2014 e pelos Jogos Olímpicos de 2016 porém contestadas pela população até chegar à opção pela candidatura de Fernando Haddad em detrimento da de Ciro Gomes em 2018, não existe desenho político progressista no Brasil sem o PT. Logo, cabe assumir tal responsabilidade e reconhecer que as gerações mais jovens não têm o mesmo vínculo com a sigla do que aquelas crescidas no ambiente da redemocratização, por exemplo. No mesmo diapasão, o carisma incontornável da figura de Lula deve servir para impulsionar e não para asfixiar a renovação democrática. Estamos cientes de que a política não se resolve no papel, mas também de que fora dele, ou seja, sem uma profunda leitura analítica da conjuntura política (indo do presente ao passado e do passado ao presente tantas vezes quanto necessário) a direita vencerá novamente o pleito de 2022. Enquanto a esquerda ainda aparenta viver a ressaca da celebração dos bons tempos e aguarda um deus ex machina que nunca virá, a direita está reposicionada desde o golpe contra Dilma Roussef e já saiu na frente: os comportamentos de João Doria em São Paulo, Wilson Witzel no Rio de Janeiro e Rodrigo Maia à frente da Câmara dos Deputados não escondem suas intenções. 
Seria muita ingenuidade confiar que pouco mais de dez anos no poder bastaria para varrer a mentalidade racista, colonial e autoritária forjada da escravidão à ditadura no decorrer de cinquentos e vinte anos de história dos vencedores ${ }^{17}$. Foi-se o tempo em que a equação demografia e democracia era vista como perigosa (Aguiar 2011). Embora desestabilizada pelo dinheiro, a democracia nos moldes burgueses acaba por conferir ares de normalidade e de naturalidade tanto à esfera do político quanto à do econômico. Embora parte da agenda socialista ainda esteja presente nos partidos de esquerda (e, decerto, moldou as reformas mais substantivas em prol da classe trabalhadora no âmbito da social-democracia capitalista (cf. Przeworski 1989 [1985]; ver, também, Hobsbawm 1995 [1994]), uma revolução societária parece não despontar no horizonte do século XXI. Dialeticamente, entretanto, o desejo de mudança continua vivo em vários lugares e entre diversos segmentos sociais.

\section{O futuro é agora: considerações finais}

Em suma, a tarefa da esquerda não é nada fácil. A rigor, ela jamais poderia ter errado ao assumir o poder, pois o preço a ser cobrado por isto em um país tão conservador quanto reacionário certamente será alto demais ${ }^{18}$.

Contudo, no exato momento em que a pandemia do Covid-19 esgarçou a guerra civil cotidiana travada nas sombras da ideologia entre trabalhadores e patrões e que o silêncio dos bancos é tão vexaminoso quanto suas declarações ${ }^{19}$, haverá ocasião mais favorável para a esquerda brasileira agregar forças rumo a um projeto popular de justiça social, ambiental e econômica oposto ao neoliberalismo, ao neofascismo e ao neoimperialismo?

A hora é de mobilização e de conscientização. De perceber que o impeachment de Bolsonaro criará mais celeuma em torno dele e de sua família, não resolverá nenhum dos problemas do país e poderá liberar um monstro ainda pior.

As periferias metropolitanas, as populações rurais indígenas e quilombolas, a potência urgente do mulherismo, a inquietude da juventude universitária proveniente das classes trabalhadoras, a denúncia social presente nas letras de funk, rap e hip hop, as associações em defesa das minorias e contra o racismo, a agenda ambientalista, a mídia independente.... Quantos exemplos de novas linguagens serão necessários para abandonarmos velhos vícios e reconstruirmos o pensamento e a atuação dos partidos políticos de esquerda? Do contrário, a ilusão de Paschoal continuará a nos imobilizar por tempo indeterminado.

\section{BIBLIOGRAFIA}

AGAMBEN, Giorgio. Estado de exceção. Campinas: Boitempo (2004 [2003]). Tradução de Iraci D. Poleti. 
AGUIAR, Thais Florencio de. A demofobia na democracia moderna. Dados - Revista de Ciências Sociais, Rio de Janeiro, vol. 54, n.4, pp.609-650 (2011).

ARENDT, Hannah. A condição humana. 10ª ed. Rio de Janeiro: Forense Universitária (2000 [1958]). Tradução de Roberto Raposo.

ARENDT, Hannah. Entre o passado e o futuro. $2^{\text {a }}$ ed. São Paulo: Perspectiva (1972 [1968]). Tradução de Mauro W. Barbosa de Almeida com revisão de Mary Amazonas Leite de Barros.

AZEVEDO E SILVA, Fernando. Ordem do dia alusiva ao 31 de março de 1964 (2020). Disponível em https://www.defesa.gov.br/noticias/67417-ordem-do-dia-alusiva-ao-31-de-marco

BENJAMIN, Walter. Para a crítica da violência. In: BENJAMIN, Walter. Escritos sobre mito e linguagem. $2^{a}$ ed. São Paulo: Duas cidades; Editora 34 (2013 [1921]). Tradução de Suzanne Kampff Lages.

BENJAMIN, Walter. Sobre o conceito de história. In: BENJAMIN, Walter. Magia e técnica, arte e política. Obras escolhidas I. São Paulo: Brasiliense (1994 [1940]). Tradução de Sérgio Paulo Rouanet.

CHAUÍ, Marilena. Brasil: mito fundador e sociedade autoritária. São Paulo: Perseu Abramo (2000).

COSTA, Breno. Tanque cheio. Todos os conflitos de interesses de Paulo Guedes no superministério da Economia. The Intercept, 27/11/2018. Disponível em: https://theintercept.com/2018/11/27/ investimos-conflitos-interesse-guedes-ministerio-economia/

DUAILIBI, Julia. A acusadora. Revista piauí, edição 122, novembro (2016).

FANON, Frantz. Pele negra, máscaras brancas. Bahia: EDUFBA. Tradução de Renato da Silveira (2008 [1952]).

GUÉHENNO, Jean-Marie. O fim da democracia: um ensaio profundo e visionário sobre o próximo milênio. Rio de Janeiro: Bertrand Brasil (1999 [1993]). Tradução de Howard Maurice Johnson e Amaury Temporal.

HABERMAS, Jürgen. Sobre a constituição da Europa: um ensaio. São Paulo: Editora Unesp (2012 [2011]). Tradução de Denilson Luis Werle, Luiz Repa e Rúrion Melo.

HOBSBAWM, Eric. Era dos Extremos: o breve século XX: 1914-1991. Tradução de Marcos Santarrita. São Paulo: Companhia das Letras (1995 [1994]).

HÜBNER MENDES, Conrado. O entulho autoritário era estoque. Quatro cinco um. A revista dos livros, edição \#31 (2019).

KILOMBA, Grada. Memórias da plantação. Episódios de racismo cotidiano. Tradução de Jess Oliveira. Rio de Janeiro: Cobogó (2019 [2008]).

KONDER, Leandro. O PT e o poder. Jornal do Brasil, dom, 17 de junho (2001). Disponível em http:// www.artnet.com.br/gramsci/arquiv173.htm

MBEMBE, Achille. Crítica da razão negra. São Paulo: n-1 edições (2018 [2013]). Tradução de Sebastião Nascimento.

NEGRI, Antonio. De volta. Abecedário biopolítico. Entrevista a Anne Dufourmantelle. Rio de Janeiro: Record (2006 [2002]). Tradução de Clóvis Marques.

O’DONNELL, Guillermo. Delegative Democracy. Journal of Democracy, vol.5, n1, jan., pp.55-69 (1994).

OLIVEIRA, Francisco de. Entrevista (com Marcelo S. Ridenti e Flávio da S. Mendes). Caderno CRH, Salvador, v.25, 66, set./dez (2012). 
OLIVEIRA, Francisco de. $O$ momento Lênin. Novos Estudos, jul, 75 (2006).

PRZEWORSKI, Adam. Capitalismo e Social-Democracia. São Paulo: Cia. das Letras (1989 [1985]). Tradução de Laura Teixeira Motta.

RIBEIRO, Guilherme. Catarse: memória, história e autoritarismo nas eleições brasileiras de 2018. Espaço e Economia. Revista Brasileira de Geografia Econômica, 16 (2019).

SAFATLE, Vladimir. A esquerda que não teme dizer seu nome. São Paulo: Três Estrelas (2012).

SCHMITT, Carl. O nomos da Terra no direito das gentes do jus publicum europaeum. Rio de Janeiro: Contraponto/Editora da PUC (2014 [1950]). Tradução de Alexandre Franco de Sá, Bernardo Ferreira, José Maria Arruda e Pedro Hermílio Villas Bôas Castelo Branco.

SLOTERDIJK, Peter. No mesmo barco. Ensaio sobre a hiperpolítica. São Paulo: Estação Liberdade (1999 [1993]). Tradução de Claudia Cavalcanti.

SOUZA, Jessé. A elite do atraso. Da escravidão à Lava Jato. Rio de Janeiro: Leya (2017).

TODOROV, Tzvetan. Os inimigos íntimos da democracia. São Paulo: Companhia das Letras (2012). Tradução de Joana Angélica d'Avila Melo.

VALENTE, Rubens. Bolsonaro admitiu atos de indisciplina e deslealdade no Exército. Folha de $S$. Paulo, 15/05/2017. Disponível em https://www1.folha.uol.com.br/poder/2017/05/1884033bolsonaro-admitiu-atos-de-indisciplina-e-deslealdade-no-exercito.shtml

ZAVERUCHA, Jorge. Rumor de Sabres: tutela civil ou controle militar? São Paulo: Ática (1994).

\section{NOTAS}

1. Ver Dualibi (2016).

2. Proposta de Emenda Constitucional responsável por congelar os gastos públicos por vinte anos, foi contestada por amplas camadas da população.

3. Empregamos o termo a fim de sublinhar as importantes e originais teses do sociólogo Jessé Souza em sua reinterpretação política, conceitual e discursiva do Brasil (Souza 2017).

4. https://twitter.com/GeneralMourao/status/1244929367773523969

5. Ver o clássico e profundo texto de Benjamin Sobre o conceito de história (Benjamin 1944 [1940]).

6. O site The Intercept aponta a convergência entre as apostas na bolsa de valores operadas por Guedes e pela Bozano Investimentos (onde ele trabalhou nos últimos três anos) e a agenda de privatizações e de reformas por ele pretendida à frente do Ministério (cf. Costa 2018).

7. Termo cunhado por Guillermo O’Donnell (1994). Acerca da crise da democracia em uma sociedade digital ou, em outras palavras, do descompasso entre o atual arranjo econômico-social e as formas políticas vigentes, consultar Sloterdijk (1999 [1993]). Para uma crítica à corrosão promovida pelo neoliberalismo sobre a democracia, vide a constatação do ex-diplomata francês Jean-Marie Guéhenno (1999 [1993]) e a percepção aguda de Tzvetan Todorov (2012).

8. A passagem em questão foi deliberadamente redigida a fim de mostrar que a parcela da esquerda a qual integramos tem total interesse em fazer uma autocrítica em relação a esse e a outros episódios pelo simples fato de que somos radicalmente diferentes da direita, cujo hábito tanto de mascarar quanto de mergulhar na corrupção na qual diuturnamente se refastela não nos pertence em nada.

9. Em reflexão anterior sobre o emprego do termo mito associado a Bolsonaro, lemos que " (...) nunca uma palavra evocada foi capaz de expressar com tamanha perfeição as características mais horrendas da coletividade social. Mito significa estar fora da história mas, ao mesmo tempo, supostamente deter poderes para nela intervir; embaralhar infantilmente realidade e 
imaginação; perder a noção de humanidade ao clamar por um super-homem apto a solucionar tudo aquilo que soa como "problema". o mito é um clamor delirante em nome da eliminação do outro e, se porventura a tragédia começar a despontar no horizonte da morte e o tempo histórico exibir sua face irrevogável, a responsabilidade sempre poderá encontrar a desculpa de que nunca ninguém imaginou que as coisas aconteceriam de tal forma. No Brasil de Bolsonaro, na Alemanha de Hitler, nos Estados Unidos de Trump ou em qualquer país do mundo, o mito, tal como descrito acima, é o álibi perfeito do autoritarismo" (Ribeiro 2019:5). Três amostras da fertilidade aberta pela Psicanálise no entendimento da vida social encontram-se em Fanon (2008 [1952]), Kilomba (2019 [2008]) e Mbembe (2018 [2013]).

10. Embora nossa predileção pela democracia grega não seja propriamente a mesma que a de Hannah Arendt, um trecho de A condição humana parece ter sido escrito sob medida para o "mito": "O ser político, o viver numa polis, significava que tudo era decidido mediante palavras e persuasão, e não através de força ou violência. Para os gregos, forçar alguém mediante violência, ordenar ao invés de persuadir, eram modos pré-políticos de lidar com as pessoas, típicos da vida fora da polis, característicos do lar e da vida em família, na qual o chefe da casa imperava com poderes incontestes e despóticos (...)" (Arendt 2000:35-36 [1958]). Ver, também, Arendt (1972 [1968]).

11. Não seria má idéia afixar o referido artigo em cada repartição pública desse país, pois serviria como prova cabal da incongruência de Bolsonaro e de seus filhos (todos eles homens públicos cujos vencimentos são pagos com dinheiro público) todas as vezes que investirem contra o funcionalismo público. Em suas próprias palavras: “Afinal, um homem que dedica os melhores anos de sua vida à carreira militar (...) não pode simplesmente pensar em patriotismo - como querem muitos - quando não pode sequer sonhar em constituir condignamente uma família". Curiosa e "inexplicável" observação: após adentrar na vida pública como político profissional, Bolsonaro nunca mais reclamou de seu "soldo". Disponível em https://thumbs.web.sapo.io/? $\mathrm{W}=800 \& \mathrm{H}=0$ \&delay_optim=1\&epic=NzM4lhLnG6tfL+lGCHeCGgUP36yCyVqDL6P1OHyG5bmsLCu1+ASeS2XNCgNKKg5fK8qRnrqH8gBxYa13 12. Disponível em https://www1.folha.uol.com.br/poder/2017/05/1884033-bolsonaro-admitiuatos-de-indisciplina-e-deslealdade-no-exercito.shtml

13. Um bom resumo político desde o golpe contra Roussef à eleição de Bolsonaro pode ser visto no documentário Democracia em vertigem (2019) dirigido pela brasileira Petra Costa.

14. O vocábulo deseja prestar singela homenagem aos infectados e aos mortos na Itália, país de Antônio Gramsci e de larga tradição de esquerda.

15. Uma crítica contundente ao papel do Direito na estruturação política das sociedades modernas foi elaborada pelo italiano Giorgio Agamben (Agamben 2004 [2003]), cujo ponto de partida localiza-se no influente artigo Para a crítica da violência, de Walter Benjamin, para quem só o Direito possui o direito à violência. A violência seria, na verdade, a instauradora do Direito. Este, com efeito, acaba por não ser incompatível com o estado de exceção (Benjamin 2013 [1921]). Simbólica de uma leitura conservadora do Direito é a obra-prima 0 nomos da Terra, do também alemão Carl Schmitt, admitindo-o como regulador legítimo da organização espacial do poder e das sociedades (não por acaso o livro é geográfico da primeira à última linha) (Schmidt 2014 [1950]). Por sua vez, Jürgen Habermas repensa a correspondência entre soberania estatal e território nacional a fim de ampliar as noções de Direito e de Democracia visando a renovação da União Européia (Habermas 2012 [2011]). Para citar apenas um dentre inúmeros exemplos emblemáticos do abuso estatal legalizado pelo Direito, destaque-se as circunstâncias da prisão do intelectual de esquerda Antonio Negri na Itália nos anos setenta do século XX (Negri 2006 [2002]). No Brasil, Conrado Hübner Mendes aponta como nossa história constitucional oscila entre o autoritarismo e a justiça (Hübner Mendes 2019; ver, também, Zaverucha 1994), enquanto Vladimir Safatle, na esteira de Benjamin, Agamben e da crucial distinção derridiana entre justiça e direito, ressalta a necessidade de descriminalização do que está fora do Direito - a soberania popular, por exemplo (Safatle 2012:39-53). Na prática, episódio recente não deixa qualquer 
margem de dúvida sobre como o Direito atua como escudo a favor da elite do atraso: em meados de março do corrente ano, Oskar Metsavaht, fundador da grife de moda Osklen, "postou" em seu Instagram uma petição eletrônica defendendo que os recursos do fundo partidário fossem remetidos para o combate ao Covid-19. Uma seguidora considerou a atitude hipócrita, uma vez que nenhuma de suas lojas havia fechado e, portanto, os funcionários estavam em risco. Segue ipsis litteris sua réplica: "Cara moça, não teça comentários sobre o que você desconhece. Estou acionando agora o meu advogado a fim de iniciar um processo de calúnia por sua declaração". Mesmo para quem não leu a descrição de Marx n'o Capital sobre a função das poor laws na Inglaterra do século XIX, a afirmação acima pode ser sintetizada em uma expressão obstinadamente atual: luta de classes. Parênteses 1: em 2012 e 2014, a Alpargatas comprou sessenta por cento da Osklen a um custo de 318,2 milhões de reais. O total da empresa é estimado em 530,3 milhões de reais ( https://exame.abril.com.br/negocios/alpargatas-assume-controleda-osklen-com-compra-de-30/ ). Para Metsavaht, o dinheiro compra tudo - inclusive o direito de ter mais direito que os outros. Parênteses 2: ele apagou a própria postagem. Afinal, para gente como ele o Instagram serve para toda sorte de jactância, mas não admite as contradições da vida real.

16. Vide Francisco de Oliveira $(2006,2012)$.

17. Cf. Chauí (2000).

18. O conhecimento de longo alcance da realidade histórica e política brasileira levou Leandro Konder a antecipar, no ano de 2001, exatamente aquilo que não poderia ocorrer quando o PT assumisse o poder. Perdoe-nos o leitor pela extensa citação, mas estamos diante de uma aula magna. "O PT, no poder, precisa manter a serenidade e evitar cair em armadilhas e provocações, porém não pode deixar de realizar esse processo revolucionador de que as massas necessitam, e com a crescente participação delas. Assumir o poder é a meta natural dos partidos políticos. O PT não é uma exceção. Para os petistas, contudo, o risco maior é o de serem de tal modo neutralizados no exercício do poder que fiquem impossibilitados de promover as mudanças possíveis. Reduzidos a figurantes impotentes de um teatro político melancólico, sofreriam uma descaracterização. Uma perda da identidade. Se deixasse de corresponder às aspirações e aos anseios das massas, se perdesse a íntima sintonia com os movimentos sociais, se não conseguisse manter a confiança dos trabalhadores, o partido não só deixaria de crescer como definharia. Ficaria enfraquecido, anêmico. E, quando tivesse que sentar à mesa para as inevitáveis negociações, seria fatalmente obrigado a fazer concessões mais pesadas e acordos mais dolorosos do que faria se, juntamente com sua identidade, tivesse conservado sua força. Se o PT não conseguisse evitar esse desastre, as conseqüências poderiam ser terríveis. As massas que vinham se identificando com ele seriam mergulhadas na frustração, na amargura e no ceticismo. Toda a esquerda se ressentiria desse fracasso. Por isso, os de 'cima' estão se movimentando para que, se o Lula for eleito presidente, o PT só consiga fazer um governo chinfrim e se desmoralize. Por isso, a esquerda precisa se movimentar, com todas as suas energias, para que isso não aconteça" (Konder 2001).

19. Em entrevista cujas vísceras do cinismo são expostas sem qualquer pudor, Candido Bracher, presidente do Itaú Unibanco, declarou ser necessário mais investimento público junto a autônomos, hospitais e empresas como forma de superar a crise (afinal, o dogma da austeridade fiscal não se aplica a casos como este), pois "tanto a doença como o desemprego matam". Alguma coisa deve ter despertado sua memória (o receio da falta de empresas e de indivíduos para tomarem crédito emprestado a juros estratosféricos, talvez?), pois normalmente bancos não se recordam e tampouco se importam com a relação direta entre desemprego e morte. Bracher, porém, admite que o momento exige a "solidariedade das pessoas" e anuncia a "doação", por meio de suas Fundações, de 150 milhões de reais para a compra de equipamentos médicos, cestas básicas e kits de higiene visando "apoiar as comunidades mais vulneráveis" (https:// oglobo.globo.com/economia/falta-ao-governo-um-administrador-da-crise-diz-presidente-do- 
itau-24326584 ). No instante imediato em que se noticia o altruísmo do Itaú Unibanco e transfere a integral responsabilidade do Covid-19 para o Estado, é suficiente recuperarmos os números de seus lucros nos últimos anos para dissiparmos quaisquer dúvidas de que vivemos em uma grande farsa: 2013: R\$ 21,887 bilhões; 2014: R\$ 26,526 bilhões; 2015: R\$ 27,660 bilhões; 2016: R\$ 24,106 bilhões; 2017: R \$ 25,933 bilhões; 2018: R\$ 26,053 bilhões; 2019: R\$ 26,583 bilhões. Em sete anos, o lucro acumulado alcança a cifra de $\mathrm{R} \$ 178,748$ bilhões (https://economia.uol.com.br/noticias/ redacao/2020/02/11/lucro-do-itau-e-o-maior-da-historia-entre-os-bancos.htm ). Como se não bastasse, qual é a chance de descobrirmos que o campeão de captação de recursos via Lei Rouanet não é outro senão o Instituto Itaú Cultural? Para fins de encenação de doações solidárias, o erário já transferiu para seus cofres quase $\mathrm{R} \$ 145$ milhões desde 2010 (https:// www.gazetadopovo.com.br/politica/republica/bancos-privados-utilizam-lei-rouanet-parafinanciar-seus-proprios-bracos-culturais-6jhi692j35ljkxfsd8nwqabzq/). E que tal saber que entre 2013 a 2016 o primeiro lugar entre os litigantes no maior tribunal de justiça do país, o Estado de São Paulo, é, coincidentemente, o Itaú? (https://www.consumidormoderno.com.br/2018/06/28/ conheca-maiores-litigantes-relacoes-consumo/). Finalizemos voltando ao salário anual do sr. Bracher: R\$ 40,918 milhões (https://www.jornalopcao.com.br/bastidores/confira-os-salariosmilionarios-dos-presidente-do-itau-vale-e-bradesco-129143/ ).

\section{RESUMOS}

Partindo da hipótese de que um suposto impeachment de Jair Bolsonaro integra uma manobra política da direita cujo objetivo não é outro senão o de permanecer no poder, analisamos cinco efeitos negativos de sua destituição para a esquerda e para a democracia brasileira em geral.

En partant de l'hypothèse selon laquelle un éventuel impeachment de Jair Bolsonaro fait partie d'une manœuvre politique de la part de la droite afin de rester au pouvoir, on analyse cinq effets négatifs de ce mouvement pour la gauche et pour la démocratie brésilienne en générale.

Partiendo de la hipótesis de que un supuesto impeachment de Jair Bolsonaro es parte de una maniobra política de la derecha cuyo objetivo no es otro que permanecer en el poder, analizamos cinco efectos negativos de su destitución para la izquierda y para la democracia brasileña en general.

Departing from the hypothesis that an eventual impeachment of President Jair Bolsonaro is a political manoeuvre from the right in order to stay in power, I analyse five negative effects of this movement both to the left and to the Brazilian democracy as a whole. 
ÍNDICE

Mots-clés: impeachment, dictature militaire, l'élite du retard, Parti des Ouvriers, democratie brésilienne.

Palabras claves: impeachment, dictadura militar, élite atrasada, Partido dos Trabalhadores, democracia brasileña.

Palavras-chave: impeachment, ditadura militar, elite do atraso, Partido dos Trabalhadores, democracia brasileira.

Keywords: impeachment, military dictatorship, late elites, Workers Party

\section{AUTOR}

\section{GUILHERME RIBEIRO}

Doutor em Geografia pela UFF, com estágio doutoral pela Universidade de Paris-Sorbonne (Paris IV). Pós-Doutor em Geografia pela UFMG. Professor Associado II do Programa de Pós-Graduação em Geografia da Universidade Federal Rural do Rio de Janeiro (PPGGEO/UFRRJ). Email: geofilos@msn.com 